\title{
BENEFICIAL EFFECTS OF FOCUSED VERSUS RADIAL UNFOCUSED LOW ENERGY EXTRACORPOREAL SHOCK-WAVE THERAPY ON CHRONIC WOUND HEALING
}

\author{
Instar S. Waked*
}

*Assistant Professor of physical therapy, Faculty of physical therapy, Cairo University, Egypt.

\section{ABSTRACT}

Objective: the aim of this study was to compare the efficacy of focused versus radial unfocused low energy extracorporeal shock-wave therapy on chronic wound healing.

Methods: Sixty patients were randomly divided into three groups of equal number. Group A; received focused extracorporeal shockwave therapy in addition to standard care. Group B received radial extracorporeal shockwave therapy in addition to standard care. Group $C$ received standard care only. Wound surface area, wound volume were measured before and after 3 weeks.

Results: The results of study revealed that there was significant reduction of wound surface area and wound volume in radial more than focused shock wave therapy group. Conclusion; Radial extracorporal shock wave therapy may be superior compared to focused extracorporeal shock wave therapy on chronic wound healing using the same low intensity energy flux densities. Further studies are needed using different parameters and follow up.

KEY WORDS: Focused Shock Wave Therapy, Radial Shock Wave Therapy, Wound Surface Area, Wound Volume, Wound Healing.

Address for correspondence: Dr. Instar S. Waked, Assistant Professor of physical therapy, Faculty of physical therapy, Cairo University, Egypt. Address: 17th Ahmed El-Zyat Street, Faculty of Physical Therapy, Cairo University. Cairo, Egypt. Mobile No.: +966532107885 E-Mail: I.waked@mu.edu.sa

\section{Access this Article online}

\begin{tabular}{|c|c|c|}
\hline \multirow{2}{*}{$\begin{array}{c}\text { Quick Response code } \\
\text { DOI: } 10.16965 / \text { ijpr.2017.236 }\end{array}$} & \multicolumn{2}{|c|}{$\begin{array}{l}\text { International Journal of Physiotherapy and Research } \\
\text { ISSN 2321- } 1822 \\
\text { www.ijmhr.org/ijpr.html }\end{array}$} \\
\hline & $\begin{array}{l}\text { Received: 14-09-2017 } \\
\text { Peer Review: 20-09-2017 } \\
\text { Revised: None }\end{array}$ & $\begin{array}{l}\text { Accepted: } 19-10-2017 \\
\text { Published (O): 11-11-2017 } \\
\text { Published (P): 11-12-2017 }\end{array}$ \\
\hline
\end{tabular}

\section{INTRODUCTION}

Chronic wounds, which also known as ulcers, are wounds that don't heal in a predictable amount of time in the way most wounds do; wounds that do not heal within three months are often considered chronic. These wounds do not close without intervention and are sometimes unresponsive to healing interventions. Diabetic foot ulcers, pressure ulcers or pressure sores, venous leg ulcers, and sternal wound infections are all recognized as chronic wounds because their etiologies delay and prevent healing, and they persist without proper medical care $[1,2]$.
Non-healing wounds are a significant, functionally-limiting medical problem impacting the quality of life for millions of people each year. Ulceration healing and its effects on the elongation of hospitalization period is a major economic issue that faces the physical therapists and other team members of ulcers rehabilitation. Wound care is an expensive component of inpatient care and lasts for a long time that presents a critical risk factor for complications such as infection and amputation; chronic wounds also lead to marked impairment of patients' quality of life [3, 4].

Ischemia, an essential element of which is 
tissue hypoxia, has been shown to limit granulation tissue formation, diminish epithelialization and decrease biomechanical strength parameters in wounds. Reduced tissue oxygen tension has been confirmed to lower collagen synthesis in wounds, improve the activity of matrix metalloproteinase and induce abnormal expression of a variety of growth factors and cytokines within the wound [5].

Lack of perfusion decreases tissue resilience, leads to rapid death of tissue, and impedes wound healing. Wound healing and tissue regeneration depend on an adequate blood supply to the region. Ischemia due to vascular disease prevents healing by reducing the supply of oxygen, nutrients, and soluble mediators that are involved in the repair process [6].

The chronicity of ulcers and its liability to lead to amputations, coupled with the frequent need for long-term treatment require the use of therapies that are simple, effective, safe and cosmetically acceptable[7,8]. The use of new therapeutic methods may prevent progression of foot ulceration and improve health-related quality of life, thereby significantly reduce overall costs and lower-extremity amputations [9]. Nearly for the last three decades, extracorporeal shock wave therapy has been clinically implemented as an effective treatment to disintegrate urinary stones. This technology has also emerged as a safe, effective noninvasive treatment modality for several orthopedic and traumatic indications including problematic soft tissue wounds [10-13]. There are several devices with focused and unfocused shock waves that have been applied to a different group of wounds. Extracorporeal Shockwave Therapy firstly used focused shock waves. Several years ago a new kind of shockwave therapy was introduced: radial shockwave therapy. Recently, radial shockwave generators are often used because they are more affordable than focused shockwave generators. To date, there is no consensus on which more efficient radial is or focused shock wave therapy in chronic wound healing. The aim of this study was to compare the efficacy of focused versus unfocused radial shock wave therapy in chronic wound healing.

\section{PATIENTS AND METHODS}

Sixty patients (24 Female \& 36 Male) with chronic wound were included in the study. Patients were recruited from EL-Mataria Teaching Hospital, Cairo, Egypt, between 2013 and 2016. Inclusion criteria were; patients had unhealed wound more than three months, patients' age between 45 and 55 years, all patients were conscious, all patients had no diabetes or blood problems, patients signed a consent form before entering the study. Reasons for exclusion were; Patients with pacemakers, coronary bypass, pregnancy, peripheral vascular disease, diabetes, coagulation diseases or history of neoplasia, Tumor over the affected area. Also, patients with bleeding disorders, arthemia, medications that prolong blood clotting, septic infection of the joints, growing nucleus, acute inflammation with pain, osteoporosis, wound size less $1 \mathrm{~cm}$ or greater than $10 \times 20 \mathrm{~cm}$.

The patient medical profile was completed for every patient that included personal data, the main disease causing the ulcer, secondary diseases, previous treatments and their costs, and previous medications. Eligible patients were randomly divided into three groups. Group A; received Focused Extracorporeal Shockwave Therapy (ESWT) in addition to standard care. Group B received Unfocused Extracorporeal Shockwave Therapy (ESWT) in addition to standard care. Group C received standard care only. Block randomization was done through software computer program by an independent assistant researcher, but he was not involved in the treatment or the outcome assessment.

Ethical Considerations: The aims, procedures of this study were fully explained to the patients. The study was approved by local ethical committee, and it is in accordance with the Declaration of Helsinki

\section{Procedures of study:}

\section{Measurement Procedures}

Assessment of Wound surface area: Assessment of wound was done for all patients before the treatment (pre) and after three weeks of treatments (post). A digital camera was used to photograph ulcer with using macro function. The wound area and its following reductions were measured with the Rhinoceros program software running on a personal computer [14].

Wound volume measurement: Wound volume 
was measured through injection of sterilized saline into wound by using graded syring and calculated the amount of saline at each time. Measurements were done before (pre) and after three weeks of treatment (post).

Treatment Procedures: Patients in group A were received focused ESWT treatment by a PiezoWave system (Richard Wolf combines, F10 G4 focused, mobile ESWT therapy source). Parameters were used $(n=20 ; 1,000$ shocks $/ \mathrm{s}$ ession, EFD per shock 0.001-0.06 mJ/mm2, Frequency $1-8 \mathrm{~Hz}$, Pressure range $0.1-3.2 \mathrm{MPa}$ ), the treatment lasted just for two minutes. Three sessions per week for three weeks.

Patients in group B were received unfocused ESWT by Evotron electrohydraulic system (HMT, Lengwil, Switzerland), with an unfocused probe. Parameters were used $(n=20 ; 1,000$ s hocks/session, EFD per shock $0.28 \mathrm{~mJ} / \mathrm{mm} 2$, Frequency 8-12 Hz, Pressure 3.2-4.5 bar), The treatment lasted just for two minutes, three sessions per week for three weeks.

The parameters such as energy flux density, pulse number, and frequency for shock wave application were chosen based on our experience in pre-studies and on other studies relating to low-energy shock wave application. Sterile ultrasound gel was spread over the wound and covered by a sterile drape. The coupling gel was spread to provide an air-free contact for the extracorporeal shock wave therapy head and to prevent any cross-contamination of the device. The head was then moved directly around the perimeter of the wound. No local anesthetic used because low energy flux density was used during the treatment.

All three groups received standard wound treatment that consisted of a regular debridement to remove surrounding callus and local wound care by Silvercell dressing for an average of 48-72 hours, treatment of infection by appropriate systemic antibiotics.

Statistical Analysis: Data obtained were analyzed using SPSS software, statistical package for the social sciences version 20.0 (SPSS Inc., Chicago, IL, USA). Continuous variables were summarized as mean \pm standard deviation (SD) and categorical variables as frequency and percentage (\%). As data of age, duration, wound surface area and wound volume variables showed normal distribution, ANOVA test was used to detect mean differences in duration, wound surface area and wound volume between three groups. Post-Hoc test used to test differences between each pair of groups. Kruskal test was used to detect differences in wound site, underlying causative disease between three groups. P value less than 0.05 was regarded as significant.

\section{RESULTS}

Figure (1) represented the Flow chart of participants through the study. Table (1) showed statistical differences of basic demographic data for patients in three groups. The mean ages for patients in groups A, B, C were $(49.60 \pm 3.33$, $49.60 \pm 3.33,49.67 \pm 3.55)$ respectively. The mean differences of the wound duration between three groups were $(6.9 \pm 2.33,7.28 \pm 2.60,7.15 \pm 2.39)$ respectively. As shown; there were no significant differences between three groups regarding age $\&$ wound duration as $P$ value $>0.05$. Regarding distribution of sex, wound site, underlying causative disease among three groups, as shown in table (1) there were no significant differences between three groups as $P$ value $>0.05$.

Fig. 1: Flow of participants through the study.

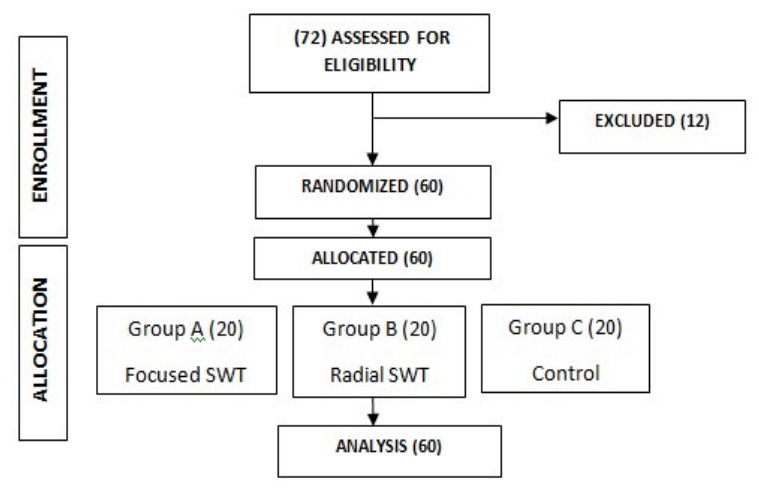

Table (2) showed statistical analysis of mean differences of wound surface area and wound volume for patients in three groups pre \& post treatment. Regarding wound surface area, there were no significant differences between three groups pre-treatment as $P$ value $>0.05$, while there were highly significant differences between three groups post- treatment as $p$ value $<0.05$. Results of wound volume among three groups showed that there were no significant 
Table 1: Represented demographic data of patients in three groups.

Table 2: Represented comparative analysis of mean differences of wound surface area and wound volume between three groups pre and post treatment.

\begin{tabular}{|c|c|c|c|c|}
\hline Variable & $\begin{array}{c}\text { Group (A) } \\
(20)\end{array}$ & $\begin{array}{c}\text { Group (B) } \\
(20)\end{array}$ & $\begin{array}{c}\text { Group (C) } \\
\text { (20) }\end{array}$ & $P$ value \\
\hline Age (years) (mean $\pm S D$ ) & $49.60 \pm 3.33$ & $50.55 \pm 2.76$ & $49.67 \pm 3.55$ & $0.661^{*}$ \\
\hline $\begin{array}{ll}\text { Sex (N) } \% \\
-\quad \text { Male } \\
-\quad \text { Female }\end{array}$ & $\begin{array}{c}\text { (13) } 65 \% \\
\text { (7) } 35 \%\end{array}$ & $\begin{array}{l}\text { (10) } 50 \% \\
\text { (10) } 50 \%\end{array}$ & $\begin{array}{l}\text { (15) } 75 \% \\
\text { (5) } 25 \%\end{array}$ & $0.421^{*}$ \\
\hline $\begin{array}{ll}\text { Site } & \text { (N) \% } \\
\text { - } & \text { Feet } \\
\text { - } & \text { Leg } \\
\text { - } & \text { Sacrum } \\
\text { - } & \text { Trochanter }\end{array}$ & $\begin{array}{l}\text { (7) } 35 \% \\
\text { (5) } 25 \% \\
\text { (5) } 25 \% \\
\text { (3) } 15 \%\end{array}$ & $\begin{array}{l}\text { (10) } 50 \% \\
\text { (6) } 30 \% \\
\text { (3) } 15 \% \\
\text { (1) } 5 \% \\
\end{array}$ & $\begin{array}{l}\text { (9) } 45 \% \\
\text { (7) } 35 \% \\
\text { (2) } 10 \% \\
\text { (2) } 10 \%\end{array}$ & $0.377^{*}$ \\
\hline $\begin{array}{ll}\text { Underlying causative disease (N) \% } \\
\text { - } & \text { Burn } \\
\text { - } & \text { Multiple sclerosis } \\
\text { - } & \text { Bilateral strokes } \\
\end{array}$ & $\begin{array}{l}\text { (9) } 45 \% \\
\text { (3) } 15 \% \\
\text { (6) } 30 \% \\
\text { (2) } 10 \% \\
\end{array}$ & $\begin{array}{l}\text { (10) } 50 \% \\
\text { (4) } 20 \% \\
\text { (2) } 10 \% \\
\text { (4) } 20 \%\end{array}$ & $\begin{array}{l}\text { (7) } 35 \% \\
\text { (3) } 15 \% \\
\text { (10) } 50 \% \\
-\end{array}$ & $0.833^{*}$ \\
\hline Duration of ulcer ) month) & $6.9 \pm 2.33$ & $7.28 \pm 2.60$ & $7.15 \pm 2.39$ & $0.900^{*}$ \\
\hline * No significant difference & & & & \\
\hline
\end{tabular}

\begin{tabular}{|c|c|c|c|c|}
\hline Variable & Group (A) (20) & Group (B) (20) & Group (C) (20) & $\begin{array}{c}\text { P value } \\
\text { between 3 } \\
\text { groups }\end{array}$ \\
\hline WSA ( pre) & $6.52 \pm 1.12$ & $6.59 \pm 1.04$ & $7.16 \pm 0.89$ & $0.171^{*}$ \\
\hline WSA (post) & $5.06 \pm 1.23$ & $3.12 \pm 0.84$ & $6.80 \pm 0.97$ & $0.0001 \dagger$ \\
\hline \% Reduction of WSA & $22 \%$ & $53 \%$ & $5 \%$ & \\
\hline WV (pre) & $17.50 \pm 1.50$ & $17.40 \pm 1.42$ & $17.30 \pm 1.30$ & $0.905^{*}$ \\
\hline WV ( post) & $9.35 \pm 3.07$ & $5.05 \pm 1.14$ & $15.05 \pm 2.11$ & $0.0001 \dagger$ \\
\hline \% Reduction of WA & $46.50 \%$ & $71 \%$ & $13 \%$ & \\
\hline \multicolumn{4}{|r|}{ * No significant difference } & † Highly significant difference \\
\hline
\end{tabular}

Table 3: Represented multiple pair comparisons by Tukey HSD test.

\begin{tabular}{|c|c|c|c|c|c|c|c|}
\hline Dependent Variable & (I) groups & (J) groups & Sig. & \begin{tabular}{|c|} 
Dependent \\
Variable \\
\end{tabular} & (I) groups & (J) groups & Sig. \\
\hline \multirow{6}{*}{$\begin{array}{l}\text { Wound surface are } \\
\text { (pre) }\end{array}$} & \multirow{2}{*}{ group A } & group B & $.400 *$ & \multirow{6}{*}{$\begin{array}{c}\text { Wound } \\
\text { volume } \\
\text { (pre) }\end{array}$} & \multirow{2}{*}{ group A } & group B & $.973^{*}$ \\
\hline & & group C & $.844^{*}$ & & & group C & $.896^{*}$ \\
\hline & \multirow{2}{*}{ group B } & group A & $.400 *$ & & \multirow{2}{*}{ group B } & group $\mathrm{A}$ & $.973^{*}$ \\
\hline & & group C & $.160^{*}$ & & & group C & $.973^{*}$ \\
\hline & \multirow{2}{*}{ group C } & group A & $.844^{*}$ & & \multirow{2}{*}{ group $C$} & group A & $.896^{*}$ \\
\hline & & group B & $.160^{*}$ & & & group B & $.973^{*}$ \\
\hline \multirow{6}{*}{$\begin{array}{l}\text { Wound surface are } \\
\text { (post) }\end{array}$} & \multirow{2}{*}{ group A } & group B & $.000 t$ & \multirow{6}{*}{$\begin{array}{c}\text { Wound } \\
\text { volume } \\
\text { (post) }\end{array}$} & \multirow{2}{*}{ group A } & group B & $.000 \dagger$ \\
\hline & & group C & $.000 t$ & & & group C & $.000 t$ \\
\hline & \multirow{2}{*}{ group B } & group A & $.000 t$ & & \multirow{2}{*}{ group B } & group A & $.000 t$ \\
\hline & & group C & $.000 t$ & & & group C & $.000 t$ \\
\hline & \multirow{2}{*}{ group C } & group A & $.000 t$ & & \multirow{2}{*}{ group C } & group A & $.000 t$ \\
\hline & & group B & $.000 t$ & & & group B & $.000 t$ \\
\hline
\end{tabular}

$*$ No significant difference + Highly significant difference

Fig. 2: Percentage of improvement of wound surface area in three groups.

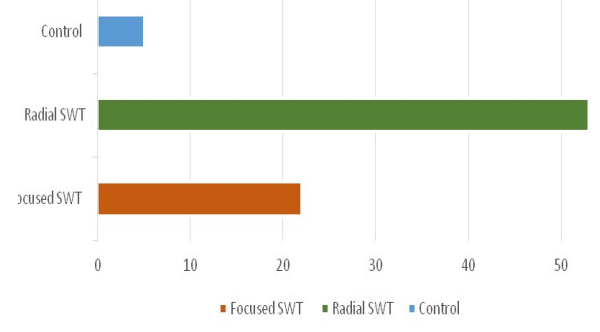

Fig. 3: Percentage of improvement of wound surface area in three groups.

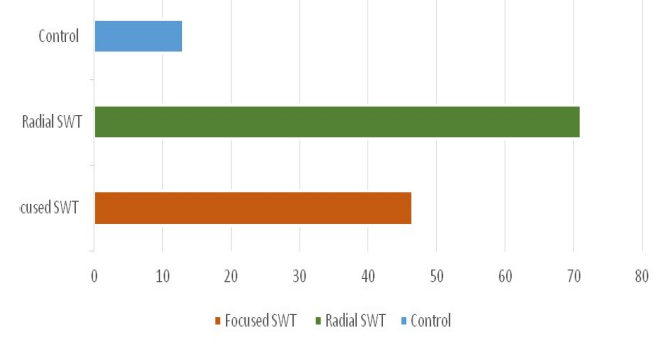


differences between three groups pre-treatment as $P$ value $>0.05$, but there were highly significant differences between three groups posttreatment as $p$ value $<0.05$. Fig (2) \& fig (3) showed the percentage of improvement between three groups.

Table (3) showed multiple pair comparisons between groups. There were highly significant differences between control group and either focused or radial shock wave group regarding wound surface area or wound volume posttreatment. In addition, there are significant differences between focused and radial shock wave group post- treatment.

\section{DISCUSSION}

Chronic wounds include, but are not limited, to diabetic foot ulcers, venous leg ulcers, and pressure ulcers. They are a challenge to wound care professionals and consume a great deal of healthcare resources around the globe. Chronic skin ulceration in long-term care is a problem as it can delay rehabilitation, time-consuming and decreases the quality of life. Therefore, it would be necessary to find therapeutic solutions able to aid the healing process by reducing, at the same time, some dressings applied, the need for assistance in wound care and the need for surgery $[15,16]$.

Chronic wound treatment is based on mechanical debridement, use of flaps or skin grafts, advanced dressings and, in an experimental way, application of a particular type of acoustic wave, defined shock wave. Nowadays ESWT can be considered an effective, safe, versatile, repeatable, noninvasive therapy for the treatment of many musculo-skeletal diseases, and for some pathological conditions where regenerative effects are desirable, especially when some other noninvasive/conservative therapies have failed $[17,18]$.

The results of this study showed significant decrease in wound surface area for focused SWT group (A) and radial SWT group (B) more than control group $(C), p$ value $<0.05$. The percentage of reduction of wound surface area for group A, group B and group C were 22\%, 53\%, 5\% respectively. In addition, the results of the study showed significant reduction in wound volume for group (A) and group (B) more than control group $(C), p$ value $<0.05$. The percentage of reduction of wound volume for group $A$, group $B$ and group $C$ were $46.5 \%, 71 \%, 13 \%$ respectively. This reflected the improvement of chronic wound healing following treatment with extracorporeal shock wave therapy, whatever focused or radial . The clinical benefits of SWT may be ascribed to its beneficial effects on the microenvironment of the wound. It stimulates physiological angiogenesis, due to the release of $\mathrm{NO}$ and vascular growth factors at the site of the ulcer. Previous studies [15, 19-26] showed that shock waves are effective in stimulating several endogenous growth factors such as EGF, IGFI, VEGF and nitric oxide production, inducing angiogenesis and promoting the healing of fractures, ulcers and complex lesions. Gerdesmeyer et al.[27] showed in their studies the antibacterial effect of shock waves mediated by cavitation. Radial shockwave generators generate waves that are very different from those generated by focused shockwave generators. Radial shockwaves lack the characteristic features of shockwaves such as a short rise-time, a high peak pressure and non-linearity [28]. Another difference is that radial shockwaves have a more superficial effect on tissue, compared to focused shockwaves which reach a maximal energy in the focus that is located deeper into the tissue [29]. These differences don't imply that radial shockwave therapy is less effective than focused shockwave therapy and each therapy may even have a different working mechanism.

To date, literature review have no studies compared both types of shock wave therapy on chronic wound treatment.

The present study revealed superiority of the radial extracorporeal shock wave treatment as compared to the focused extracorporeal shock wave treatment. Combining all tested variables (wound surface area and wound volume), resulted in a superior outcome for the group $B$ treated with radial shock waves more than group A treated by focused SWT. The percentage of reduction of wound surface area and wound volume for focused SWT were 22\%, $46.5 \%$ respectively while for radial SWT were 53\%, 71\%. No side effects or discomforts were reported in both groups because of SWT application. 


\section{CONCLUSION}

Radial extracorporal shock wave therapy may be superior compared to focused extracorporeal shock wave therapy on chronic wound healing using the same low intensity energy flux densities. Further studies are needed using different parameters and follow up .

\section{Conflicts of interest: None}

\section{REFERENCES}

[1]. Snyder, Robert J. Treatment of nonhealing ulcers w ith allografts. Clinics in Dermatology 2005;23 (4): 388-95.

[2]. Moreo, Kathleen. Understanding and overcoming the challenges of effective case management for patients with chronic wounds. The Case Manager 2005;16(2):62-3.

[3]. Ashford RL, McGee P, Kinmond K. perception of quality of life by patients with diabetic foot ulcers. The diabetic foot: 2000;3(4):150-5.

[4]. Wu S, Armstrong DG: Risk assessment of the diabetic foot and Wound .Int Wound J 2005;2:17-24.

[5]. Volk SW, Radu A, Zhang L, Liechty KW. Stromal progenitor cell therapy corrects the wound healing defect in the ischemic rabbit ear model of chronic wound repair. Wound Rep Reg 2007;15:736-47.

[6]. Sumpio B. E., J. Aruny, P. A. Blume: The Multidisciplinary Approach to Limb Salvage. Centers for Vascular Disease and Diabetic Limb Preservation, USA. Acta chir belg 2004;104:647-653.

[7]. Leila Yazdanpanah, Morteza Nasiri, and Sara Adarvishi, Literature review on the management of diabetic foot ulcer, World J Diabetes. 2015 Feb 15; (1):37-53.

[8]. Stephanie C Wu, Vickie R Driver, James S Wrobel, and David G Armstrong, Foot ulcers in the diabetic patient, prevention and treatment, Vasc Health Risk Manag. 2007 Feb;3(1):65-76.

[9]. Tantawi T.I, Gohar Y.M, Kotb M.M , Beshara F.M, ElNaggar M.M: Clinical and microbiological efficacy of MDT in the treatment of diabetic foot ulcers J. of Wound Care Supp. 2007;16(9).

[10]. Hess L.C., Howard AM., and Attinger EC., A Review of Mechanical Adjunct in Wound Healing: Hydrotherapy, Hyperbaric Oxygen and Electro-Stimulation. Ann Plast Surg,2000;51:210-218.

[11]. Qureshi AA, Ross KM, Ogawa R, Orgill D. Shock wave therapy in wound healing. Plast Reconstr Surg. 2011;128(6):721e-7.

[12]. Fioramonti P, Onesti MG, Fino P, Fallico N, Scuderi $\mathrm{N}$. Extracorporeal shock wave therapy for the treatment of venous ulcers in the lower limbs. Ann Ital Chir. 2012;83(1):41-4.

[13]. Mittermayr R, Antonic V, Hartinger J, Kaufmann H, Redl $H$, Téot $L$, et al. Extracorporeal shock wave therapy (ESWT) for wound healing: technology, mechanisms, and clinical efficacy. Wound Repair Regen. 2012;20(4):456-65.
[14]. Moretti, B., Notarnicola, A., Maggio, G. et al. BMC Musculoskelet Disord, 2009;10:54.

[15]. Saggini R, Figus A, Troceóla A, Coco V, Saggini A, Scuderi N. Extracorporeal shock wave therapy for management of chronic ulcers in the lower extremities. Ultrasound Med Biol 2008;34(8):1261-71.

[16]. Larking AM, Duport S, Clinton M, Hardy M, Andrews K. Randomized control of extracorporeal shock wave therapy versus placebo for chronic decubitus ulcération. Clinical Rehabilitation 2010;24:222-29.

[17]. Wang.J., Extracorporeal shockwave therapy in musculoskeletal disorders, J. Orthop. Surg. Res. 2012;7(11).

[18]. Cacchio, L. Giordano, O. Colafarina, J.D. Rompe, E. Tavernese, F. Ioppolo, S. Flamini, G. Spacca, V. Santilli, Extracorporeal shock-wave therapy compared with surgery for hypertrophic long-bone nonunions, J. Bone Jt. Surg. Am. 2009;91(11):2589-2597.

[19]. Ma HZ, Zeng BF, Li XL. Upregulation of VEGF in subchondral bone of necrotic femoral heads in rabbits with use of extracorporeal shock waves. CalcifTissue Int 2007;81:124-31.

[20]. Keil H, Mueller W, Herold-Mende C, Gebhard MM, Germann G, Engel H, Reichenberger MA. Preoperative shock wave treatment enhances ischémie tissue survival, blood flow and angiogenesis in a rat skin flap model. Int J Surg 2011;9(4):292-6

[21]. Zins SR, Amare MF, Tadaki DK, Elster EA, Davis TA. Comparative analysis of angiogenie gene expression in normal and impaired wound healing in diabetic miee: effects of extracorporeal shock wave therapy. Angiogenesis 2010;13(4):293-304.

[22]. Stojadinovie A, Elster EA, Anam K, Tadaki D, Amare $M$, Zins S, Davis TA. Angiogenic response to extracorporeal shock wave treatment in murine skin isografts. Angiogenesis 2008; II(4):369-80.

[23]. Silveira A, Koenig JB, Arroyo LG, Trout D, Moens NM, LaMarre J, Brooks A. Effeets of unfocused extracorporeal shock wave therapy on healing of wounds of the distal portion of the forelimb in horses. Am J Vet Res 2010;71(2):229-34.

[24]. Morgan DD, McClure S, Yaeger MJ, Schumacher J, Evans RB. Effects of extracorporeal shock wave therapy on wounds of the distal portion of the limbs in horses. J Am Vet Med Assoc 2009;234(9):115461.

[25]. Tinazzi E, Amelio E, Marangoni E, et al. Effects of shock wave therapy in the skin of patients with progressive systemic sclerosis: a pilot study. Rheumatol Int 2011;31(5):651-6 16.

[26]. Yan X, Zeng B, Chai Y, Luo C, Li X. Improvement of blood flow, expression of nitric oxide, and vascular endothelial growth factor by low-energy Shockwave therapy in random-pattern skin flap model. Ann Plast Surg 2008;61(6):646-53.

[27]. Gerdesmeyer L, von Eiff C, Horn C, Henne M, Roessner M, Diehl P, Gollwitzer H. Antibacterial effects of extracorporeal shoek WAVES. Ultrasound in Med Biol 2005;31:115-19. 
[28]. Cleveland RO, Chitnis PV, McClure SR. Acoustic field of a ballistic shock wave therapy device. Ultrasound Med Biol. 2007;33(8):1327-1335.

[29]. McClure S, Dorfmnller C. Extracorporeal shock wave therapy: Theory and equipment. Clinical Techniques in Equine Practice. 2003;2(4):348-357.

How to cite this article:

Instar S. Waked BENEFICIAL EFFECTS OF FOCUSED VERSUS RADIAL UNFOCUSED LOW ENERGY EXTRACORPOREAL SHOCK-WAVE THERAPY ON CHRONIC WOUND HEALING. Int J Physiother Res 2017;5(6):2501-2507. DOI: 10.16965/ijpr.2017.236 